


\section{ECONOMIC AND FISCAL IMPACTS OF DISASTERS IN THE PACIFIC}

APRIL 2018 
(C) 2018 Asian Development Bank 6 ADB Avenue, Mandaluyong City, 1550 Metro Manila, Philippines

Tel +632632 4444; Fax +6326362444

www.adb.org

Some rights reserved. Published in 2018.

ISBN 978-92-9261-118-7 (print), 978-92-9261-119-4 (electronic)

Publication Stock No. TCS189300-2

DOI: http://dx.doi.org/10.22617/TCS189300-2

The views expressed in this publication are those of the authors and do not necessarily reflect the views and policies of the Asian Development Bank (ADB) or its Board of Governors or the governments they represent.

ADB does not guarantee the accuracy of the data included in this publication and accepts no responsibility for any consequence of their use. The mention of specific companies or products of manufacturers does not imply that they are endorsed or recommended by ADB in preference to others of a similar nature that are not mentioned.

By making any designation of or reference to a particular territory or geographic area, or by using the term "country" in this document, $A D B$ does not intend to make any judgments as to the legal or other status of any territory or area.

This work is available under the Creative Commons Attribution 3.0 IGO license (CC BY 3.0 IGO)

https://creativecommons.org/licenses/by/3.0/igo/. By using the content of this publication, you agree to be bound by the terms of this license. For attribution, translations, adaptations, and permissions, please read the provisions and terms of use at https://www.adb.org/terms-use\#openaccess.

This CC license does not apply to non-ADB copyright materials in this publication. If the material is attributed to another source, please contact the copyright owner or publisher of that source for permission to reproduce it. ADB cannot be held liable for any claims that arise as a result of your use of the material.

Please contact pubsmarketing@adb.org if you have questions or comments with respect to content, or if you wish to obtain copyright permission for your intended use that does not fall within these terms, or for permission to use the ADB logo.

Notes:

In this publication, "\$” refers to United States dollars.

Corrigenda to ADB publications may be found at http://www.adb.org/publications/corrigenda.

All photos, including the cover, are from ADB unless otherwise stated. 


\section{Contents}

TABLE, FIGURES, AND BOX iv

FOREWORD

ACKNOWLEDGMENTS vi

INTRODUCTION

UNDERSTANDING DISASTERS IN THE PACIFIC: HAZARDS, RISKS, AND CLIMATE CHANGE 2

RESOURCES FOR ASSESSING DISASTER IMPACTS IN THE PACIFIC $\quad 7$

TYPOLOGY OF DISASTER IMPACTS: DIRECT DAMAGES AND ECONOMIC LOSSES 10

FISCAL IMPACTS OF DISASTERS IN THE PACIFIC

BUILDING FINANCIAL RESILIENCE IN THE PACIFIC

TOOL KIT FOR FINANCIAL RESILIENCE IN THE PACIFIC 16 


\section{Table, Figures, and Box}

\section{TABLE}

Tool Kit for Financial Resilience in the Pacific

\section{FIGURES}

1 Comparing Disaster Impacts in the Pacific to International Averages

Total Life-Years Lost Due to Direct Impacts of Disaster Events

2 Assessing Disaster Risk 4

3 Climate Change Issues in the Pacific 5

4 Typology of Disaster Impacts 10

5 Applying the Tool Kit to Varying Disaster Types 20

\section{BOX}

Strengthening Resilience with Planning and Proactive Investments 


\section{Foreword}

limate change and natural disasters can have lasting consequences on livelihoods, economies, and fiscal balances-spanning immediate reconstruction costs and fiscal shocks to long-term halts in tourism and agriculture economies. Although countries in the Pacific are the most exposed, globally, to these impacts, they have severely limited resources with which to prepare for and respond to them.

The Asian Development Bank is working closely with its Pacific developing member countries to prepare for and respond to the effects of climate change and natural hazards. Resilience planning often focuses on policy measures and physical interventions to safeguard communities and infrastructure. However, there is a limited body of research to address the fiscal and economic impacts of disasters, particularly in the Pacific.

This publication analyzes the vulnerability of Pacific economies to climate change and disaster events, and identifies existing resources for responding to economic shocks. It also considers measures that public and private sector stakeholders can take to develop new tools to increase economic and fiscal resilience across the Pacific region.

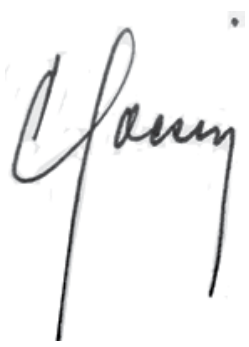

\section{Ma. Carmela Locsin}

Director General

Pacific Department

Asian Development Bank 


\section{Acknowledgments}

his publication is based on research and an unpublished report by llan Noy, Chair in the Economics of Disasters and Professor of Economics, Victoria University of Wellington. Roble Poe Velasco-Rosenheim, Staff Consultant to the Pacific Department (PARD), wrote this publication under the direction of Emma Veve, Director, Urban, Social Development, and Public Management Division, PARD. The publication was prepared under the Pacific Economic Management (Phase 2) technical assistance, and benefited from input from the Department of Communications. Ricardo Chan, ADB consultant editor, edited the final text, and Cecil C. Caparas, Associate Knowledge Management Officer, PARD managed the publication process. PARD wishes to thank Charlotte Benson and Christian Ellerman from the Sustainable Development and Climate Change Department, for reviewing the report. 


\section{Introduction}

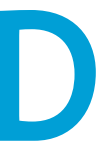

isaster events have lasting impacts on people, communities, and socioeconomic development. Countries in the Pacific are among the most exposed, globally, to natural disasters, including floods, droughts, cyclones, and earthquakes. The effects of climate change threaten to increase the severity and frequency of hazard events in the Pacific region, emphasizing the need for Pacific island countries to protect themselves against corresponding social and economic consequences.

Given the large role of the public sector in most Pacific economies, reducing the financial exposure of governments to disaster risk is essential for safeguarding sustainable development. Preparing for risks enables countries to minimize damages and immediate impacts on people and communities. Ensuring financial preparedness allows governments to quickly respond to disasters, and to minimize secondary impacts on the economy. As such, disaster risk reduction is essential both for attenuating immediate impacts on people and assets, and for supporting communities to swiftly recover.

The Asian Development Bank is working with its Pacific developing member countries to increase resilience across the region. Some of the key measures for doing so include climate-proofing assets and investments; raising awareness; and building the capacity of stakeholders to plan for, manage, and respond to disasters. Lack of financial preparedness to respond to disasters remains a central constraint for governments across the Pacific. Building a robust understanding of available financial tools and resources is essential for planning for and responding to disaster events.

This publication seeks to support governments in the Pacific in planning policies and allocating resources to reduce the economic impacts of disaster events. It describes the potential direct and secondary effects of natural disasters on Pacific developing member countries, and explains how climate change may affect risk profiles. It also provides an overview of existing resources that stakeholders in the Pacific can use to assess risk and plan for disaster events. The Tool Kit for Financial Resilience (pages 16-21) provides an overview of key instruments that policy makers can use to transfer risk and reduce the economic and fiscal impacts of disasters.

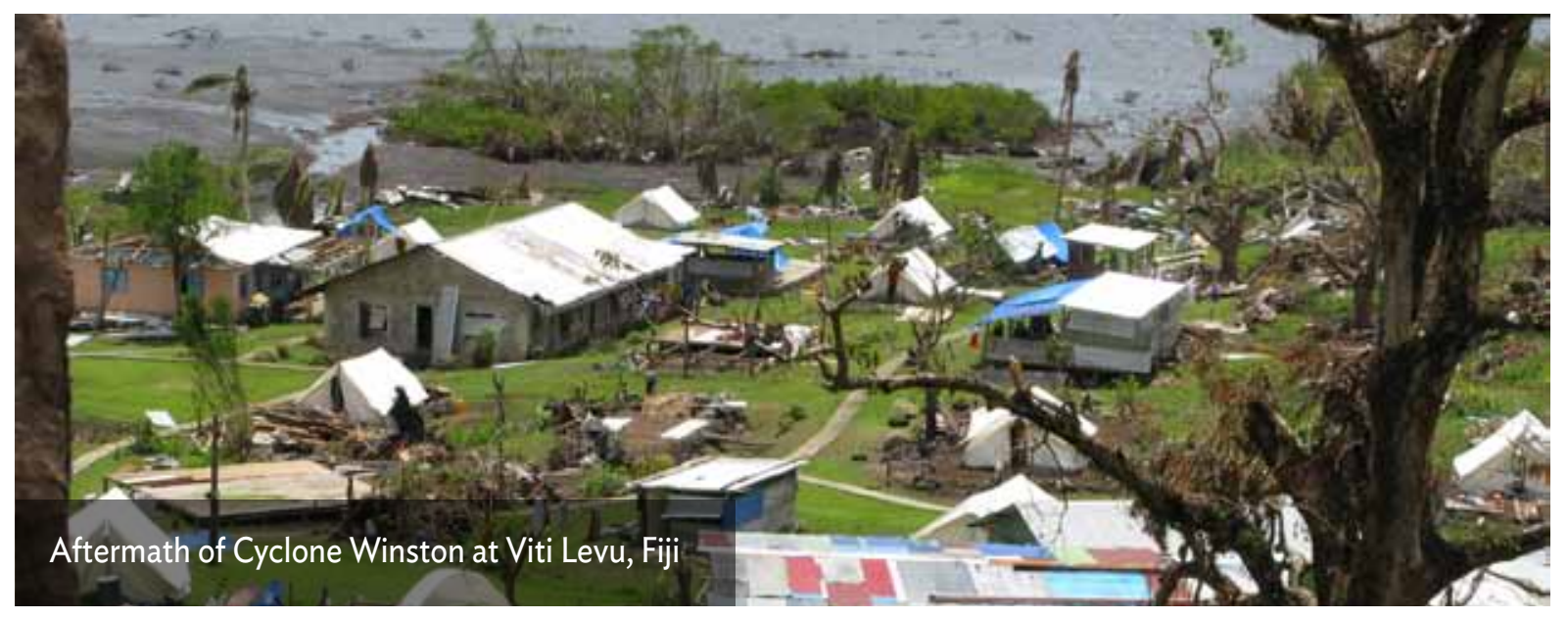




\section{Understanding Disasters in the Pacific: Hazards, Risks, and Climate Change}

T he Pacific developing member countries (DMCs) of the Asian Development Bank (ADB) comprise geographically dispersed island nations, spread across a vast ocean area. Pacific DMCs typically have small economies, and narrow resource bases. These factors compound challenges associated with restoring economic and national development activities following disaster events. Sound policy and resource management can significantly reduce the impacts of disasters on people and economies across the region.

\section{Understanding Hazards}

The United Nations Office for Disaster Reduction (UNISDR) defines hazards as "a process, phenomenon or human activity that may cause loss of life, injury or other health impacts, property damage, social and economic disruption or environmental degradation." A disaster, in turn, is "a serious disruption of the functioning of a community or a society at any scale due to hazardous events ... leading to one or more of the following: human, material, economic and environmental losses and impacts" (footnote 1).

The Pacific island countries face the highest disaster risk, in per capita terms, globally (Figure 1). Frequent lowimpact disaster events create significant fiscal burdens for governments in the Pacific and impede development in the region. Less-frequent, higher-impact events inflict acute damage on communities, infrastructure, and economies, further exacerbating fiscal burdens and slowing the development process.

High-impact, low-frequency hazard events. Most of ADB's Pacific DMCs are located along the cyclone belt and are either on or near the tectonic boundary between the Australian and Pacific plates, which expose them to catastrophic events such as earthquakes and cyclones. Given their placement, Pacific DMCs are also vulnerable to tsunamis and storm surges generated offshore. Examples of recent catastrophic events in the region include the 2009 tsunami in Samoa; the 2015 cyclone in Kiribati, Tuvalu, and Vanuatu (Cyclone Pam); and the 2016 cyclone in Fiji (Cyclone Winston).

ADB's 14 Pacific DMCs comprise the Cook Islands, Fiji, Kiribati, the Marshall Islands, the Federated States of Micronesia, Nauru, Palau, Papua New Guinea, Samoa, Solomon Islands, Timor-Leste, Tonga, Tuvalu, and Vanuatu.

2 UNISDR. Terminology on Disaster Risk Reduction. https://www.unisdr.org/we/inform/terminology.

UNISDR provides a glossary of terms that are commonly used to describe disaster risk reduction. The present publication uses definitions from this glossary (with appropriate citation) to be consistent with terms used by other development partners and international organizations. 


\section{Figure 1: Comparing Disaster Impacts in the Pacific to International Averages}

Total Life-Years Lost Due to Direct Impacts of Disaster Events (1980-2012, average)

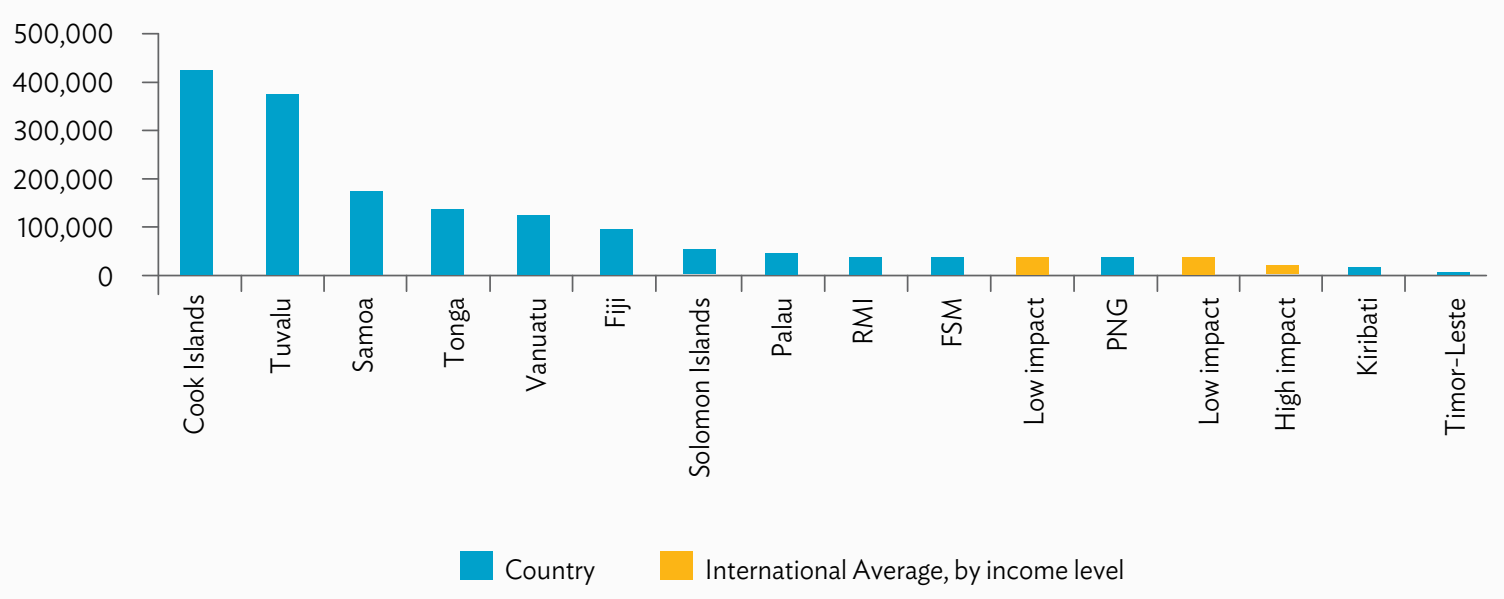

FSM = Federated States of Micronesia, PNG = Papua New Guinea, RMI = Republic of the Marshall Islands.

Note: Cumulative damages are measured in life-years, based on a calculation methodology outlined in I. Noy. 2014. A Non-Monetary Global Measure of the Direct Impact of Natural Disasters. Background Paper for the Global Assessment Report on Disaster Risk Reduction. 2015. Geneva.

Source: ADB. 2015. Pacific Economic Monitor: Midyear Review, July 2015. Manila.

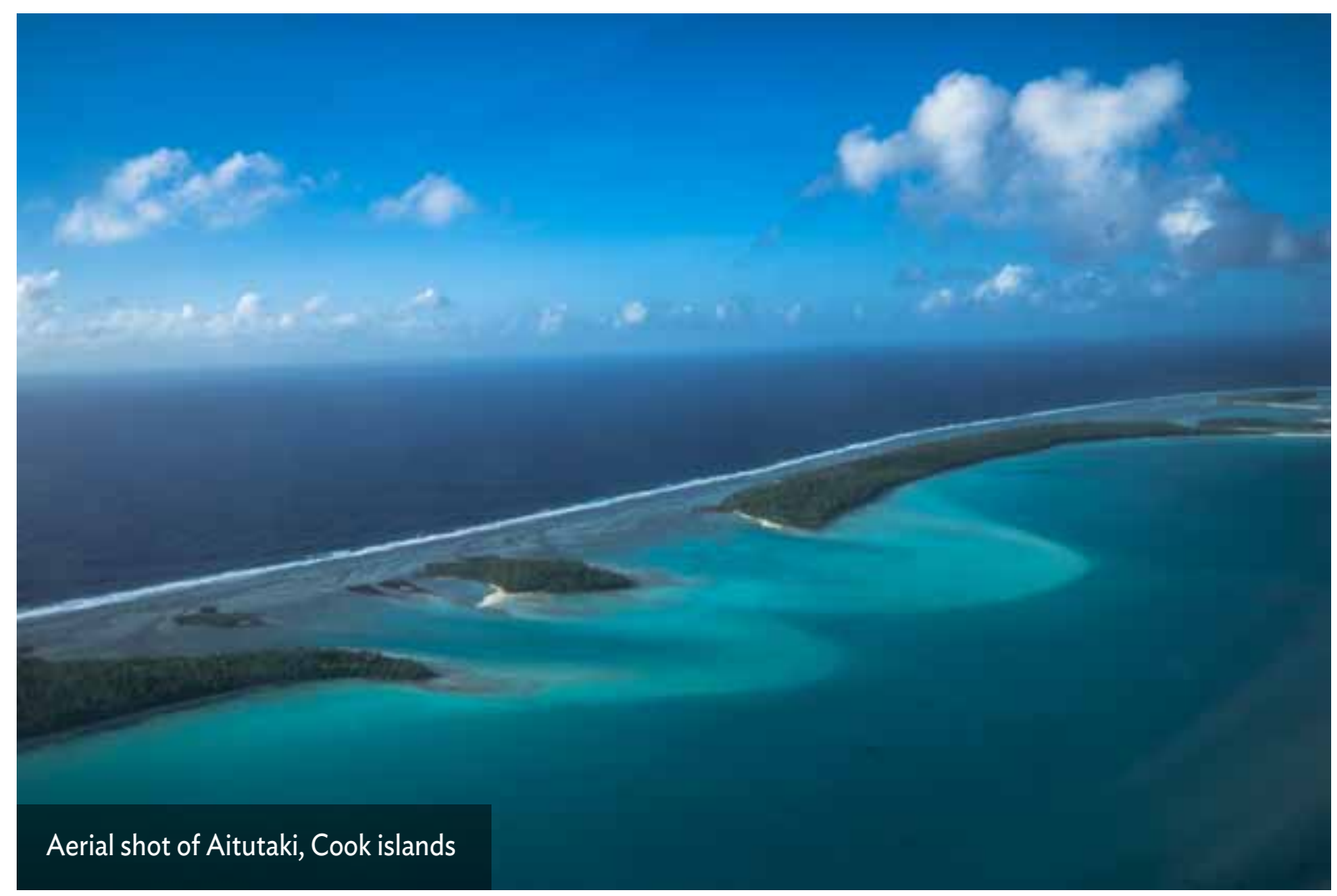


Low-impact, high-frequency hazard events. In addition to severe catastrophic events, countries in the Pacific are also affected by frequent natural hazards of smaller magnitudes, which include seasonal high tides (king tides), floods, extreme heat days, and periodic droughts that are often associated with the El Nino-Southern Oscillation phenomenon. ${ }^{3}$

Many Pacific DMCs rely on rainfall for their water consumption and agricultural needs, which increases their vulnerability to droughts, while populations living in river valleys are exposed to rain-induced flooding. The smaller coral atolls countries in the Pacific are particularly vulnerable to these hazards, and projected sea-level rise will exacerbate their exposure to hazards.

\section{Assessing Disaster Risk}

Disaster risk expresses the likelihood of a community or system to incur damages during or after a disaster, and their ability to withstand and recover from them. Risk can be assessed as a function of three variables (Figure 2).

(i) The hazard profile of a country or region. The hazard profile of a country or community is a function of geographical placement, geophysical characteristics, and climatic conditions. As such, hazard profiles are largely predetermined, and cannot be directly addressed by human activity, at least from short to medium term. The placement of many Pacific island countries along tectonic boundaries, and in tropical zones, makes them some of the most hazard-prone countries in the world. The effects of climate change may increase the likelihood and severity of hazard events.

(ii) The exposure of populations and assets to hazards. Exposure is primarily determined by the location of people and assets within an area affected by a hazard. For example, movement to areas that are likely to incur more severe damages during a hazard event-such as steep hillside communities or floodplainsincreases exposure. The placement of many Pacific populations along coasts or in steep river valleys increases their exposure to the impacts of hazards.

(iii) The vulnerability of a population or system to disasters. Vulnerability considers the ability of a population to withstand a hazard event; and to reduce its social, economic, and personal impacts. The vulnerability of a given population to the short-term impacts of a disaster can be different from their vulnerability to long-term impacts. ${ }^{4}$ Most Pacific countries are spread across large ocean areas, which makes it difficult for central governments to provide timely assistance to outlying

\section{Figure 2: Assessing Disaster Risk}

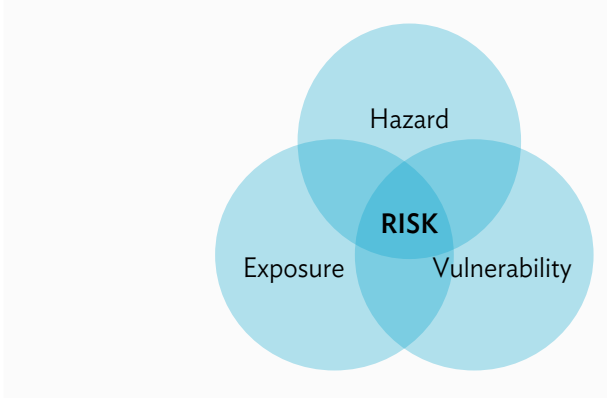

Source: Author. islands.

If El Nino Southern Oscillation events occur more frequently, or if they become more severe, the Pacific may experience a higher frequency of flash floods and droughts, more intense cyclones with changing trajectories, and further deterioration of ocean ecology.

$4 \quad$ D. Crichton. 1999. The Risk Triangle. In J. Ingleton, ed. Natural Disaster Management. London: Tudor Rose (pp.102-103). 


\section{The Effects of Climate Change on Disasters in the Pacific}

Changing weather patterns are likely to affect the frequency and intensity of hazard events. In addition, sea-level rise and increasing ocean temperatures may affect the exposure of Pacific communities to hazard events. As such, the effects of climate change may tangibly increase the risk profiles of Pacific DMCs, emphasizing the need to build resilience to minimize the vulnerability and risk profiles of Pacific DMCs.

The four most relevant threats, with respect to likely changes in hazards facing the Pacific, are (i) increases in temperatures and frequency of extremely hot days; (ii) changes in frequency and intensity of extreme rainfall events, and corresponding flash floods or droughts; (iii) changes in the frequency, intensity, and trajectories of tropical cyclones; and (iv) sea-level rise and the degradation of marine environments. ${ }^{5}$

Cyclones. Cyclones pose severe threats to communities across the Pacific, and predictions suggest a global increase in the impacts of cyclones over the coming decades. Although predictions indicate no change, or even a small decrease in the frequency of storms, they signal a $2 \%-11 \%$ increase in wind intensity. ${ }^{6}$ Since wind speed has a positive, nonlinear correlation to damages, higher storm intensity may lead to exponentially higher damages.

In addition to greater storm intensity, predictions indicate that cyclone trajectories will change in the coming decades. Different models project different trajectories. Some indicate poleward shifts, while others suggest equatorial, or eastward shifts. However, the underlying prediction that changing weather patterns will affect storm paths signals the need to strengthen disaster risk mitigation efforts both in and beyond the Pacific.?

Countries and regions that are unaccustomed to cyclones-and are, therefore, less prepared to respond to them-experience the highest rates of mortality, morbidity, and damages. Although most Pacific DMCs are accustomed to cyclones, it is essential that policy makers and development partners continue strengthening risk preparedness to mitigate and respond to immediate damages and secondary impacts.

5 For more information concerning economic impacts of extreme heat days and changing rainfall patterns: ADB. 2013. The Economics of Climate Change in the Pacific. Manila.

6 Australian Bureau of Meteorology and Commonwealth Scientific and Industrial Research Organisation. 2014. Climate Variability, Extremes and Change in the Western Tropical Pacific: New Science and Updated Country Reports. Pacific-Australia Climate Change Science and Adaptation Planning Program Technical Report. Melbourne; J.D. Woodruff., J.L. Irish, and S.J. Camargo. 2013. Coastal flooding by tropical cyclones and sea-level rise. Nature. 504.; J. Weinkle, R. Maue, and R. Pielke Jr. 2012. Historical Global Tropical Cyclone Landfalls. Journal of Climate. 25, pp. 4729-4735; and V. Thomas, J.R.G. Albert, C Hepburn. 2014. Contributors to the frequency of intense climate disasters in Asia-Pacific countries. Climate Change. 126. pp. 381-398.

K. Nam-Young and J. B. Elsner. 2015. Trade-off Between Intensity and Frequency of Global Tropical Cyclones. Nature Climate Change. 5. pp. 661-664. 


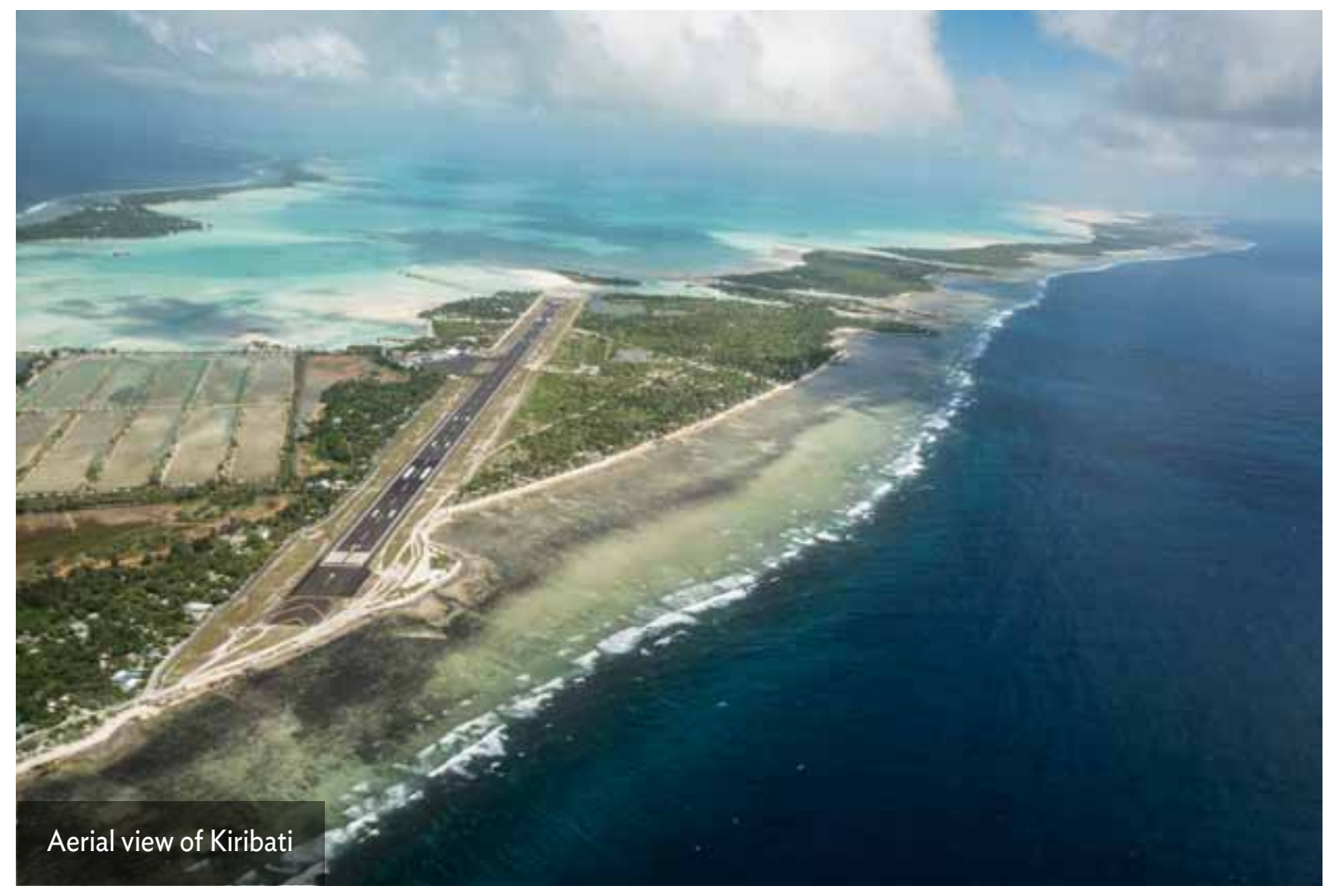

Changing marine environments. Sea-level rise and deteriorating marine environments increase exposure and risk profiles, particularly for coastal communities and atoll nations. Rising sea levels can increase the damages from wave surges caused by storms and earthquakes, and-due to their low-lying topography-atolls are particularly vulnerable to increasing sea levels, even at magnitudes that would pose relatively minor threats to other geological formations. Atoll islands already suffer damages during king tides, and sea-level rise will magnify these events.

Coral reefs attenuate as much as $97 \%$ of wave power caused by storms, and reduce wave height by approximately $85 \% .^{8}$ The deterioration of coral reefs and mangrove ecosystems leaves coastal areas considerably more exposed to wave surges, independent of the changing frequency and intensity of storms and other hazards.

8 F. Ferrario et al. 2013. The Effectiveness of Coral Reefs for Coastal Hazard Risk Reduction and Adaptation. Nature Communication. 


\section{Resources for Assessing Disaster Impacts in the Pacific}

nderstanding the historical trend of disaster impacts is essential for reducing risks, and for minimizing impacts on communities and economies. There are several loss databases that collate international disaster impact information and, although each platform has limitations, they are essential tools for building resilience and reducing impacts on lives and economies. As governments and development partners continue to strengthen disaster risk reduction (DRR) measures, there is a growing need to produce accurate and consistent assessments of disasters impacts, and to share best practices in responding to them. ${ }^{9}$

\section{Overview of Existing Resources}

Quantifying disaster damages is inherently difficult, in part because there is little agreement on what should be counted, and because different stakeholders draw data from distinct sources. There are two primary international resources that collect disaster impact data, and one emergent tool for assessing disaster risk in the Pacific. The two international tools-the Emergency Events Database (EM-DAT) and the Disaster Inventory System (DesInventar) - provide an extensive pool of information on disaster impacts, but fail to capture the full extent of damages in the Pacific.

Since the two databases use different definitions of terms and collect data from different sources, there are discrepancies between their assessments of specific disaster impacts, as well as cumulative damage assessments for countries. Harmonizing data collection practices, and increasing accuracy of data can significantly help Pacific DMCs plan for, and respond to disaster risks.

The Pacific Catastrophe Risk Assessment and Finance Initiative (PCRAFI) is a collaborative effort between development partners and the Secretariat of the Pacific Community. It seeks to overcome some of the existing constraints in collecting data on disaster impacts, and to support Pacific DMCs in mitigating short- and longterm fiscal impacts associated with disasters.

\section{The Emergency Events Database}

EM-DAT is the most frequently used resource for disaster data. It captures the number of people killed, the number of people affected, and the estimated sum of immediate economic damages to infrastructure and

9 In this publication, DRR indicates any effort to reduce or improve the management of disaster risk, including disaster risk mitigation and management efforts. 
assets. For a disaster event to be included in EM-DAT, however, it must meet one or more of the following criteria: (i) 10 or more people are reported killed, (ii) 100 people are reported affected, (iii) a state of emergency is declared, or (iv) a call for international assistance is issued..$^{10}$ These criteria typically limit the scope of disasters in EM-DAT to high-impact, low-frequency events. Since high-frequency, low-impact events represent considerable economic burdens for governments in the Pacific, EM-DAT does not capture the full range of disaster impacts in the region.

The Centre for Research on the Epidemiology of Disasters manages EM-DAT, and its staff are responsible for aggregating and entering all relevant information into the database. As such, the information entered for each disaster is contingent on the center's available resources. Historically, this has led to limited information on disasters in Pacific DMCs, and potential underreporting of damages. Although EM-DAT is a key tool for archiving disaster information, resource constraints and reporting criteria limit its ability to capture the full range of disaster impacts in the region.

\section{The Disaster Inventory System}

DesInventar is another essential tool for quantifying disaster impacts. UNISDR manages DesInventar, and works with government agencies and regional stakeholders to aggregate data. In the Pacific, DesInventar primarily draws on data from the Geoscience Division of the Secretariat of the Pacific Community, and appears to report on a wider range of hazard events than EM-DAT, including a number of low-impact, high-frequency events.

Although DesInventar collects data on a wider range of disaster events, discrepancies between impact data pertaining to similar hazards in different countries suggest that data collection practices are not always consistent, which prevents accurate comparison of historical disaster burdens across countries.

\section{The Pacific Catastrophe Risk Assessment and Finance Initiative}

PCRAFI is a collaborative platform, which seeks to "provide PICs (Pacific island countries) with disaster risk modeling and assessment tools. It also aims to engage in a dialogue with PICs on integrated financial solutions for the reduction of their financial vulnerability to natural disasters and to climate change."11

PCRAFI assesses risks based on cyclone, earthquake, and tsunami modeling, and provides comprehensive mapping of physical assets across the Pacific. ${ }^{12}$ The initiative, which covers all Pacific DMCs and Niue, identifies exposure (location of potentially vulnerable people and assets); and provides an assessment of hazards (such as expected frequency, intensity, and location) for each country. ${ }^{13}$

\footnotetext{
Centre for Research on the Epidemiology of Disasters. Emergency Events Database. http://www.emdat.be/.

PCRAFI. About page. http://pcrafi.spc.int/about/.

PCRAFI. 2013. Catastrophe Risk Assessment Methodology. Pacific Catastrophe Risk Assessment and Financing Initiative. Washington D.C. (June).

Air Worldwide. 2010. Pacific Catastrophe Risk Assessment and Financing Initiative (PCRAFI) Component 1: Hazard Data and Loss Data Collection and Management. Technical report submitted to the World Bank; and Air Worldwide. 2011. Pacific Catastrophe Risk Assessment and Financing Initiative

(PCRAFI) Component 2: Exposure Data Collection and Management. Technical report submitted to the World Bank.
} 
PCRAFI provides a detailed assessment of current disaster risks from primary hazards in the Pacific, including cyclones, earthquakes, and tsunamis, based on climate and earthquake modeling, and a comprehensive map of physical assets in the Pacific. By combining data on exposed assets, vulnerability curves, and hazards, PCRAFI provides detailed risk profiles, which include estimates of damages based on various scenarios. The platform is being used to support improved land-use policies and financial risk management, and to prioritize investments in resilient infrastructure.
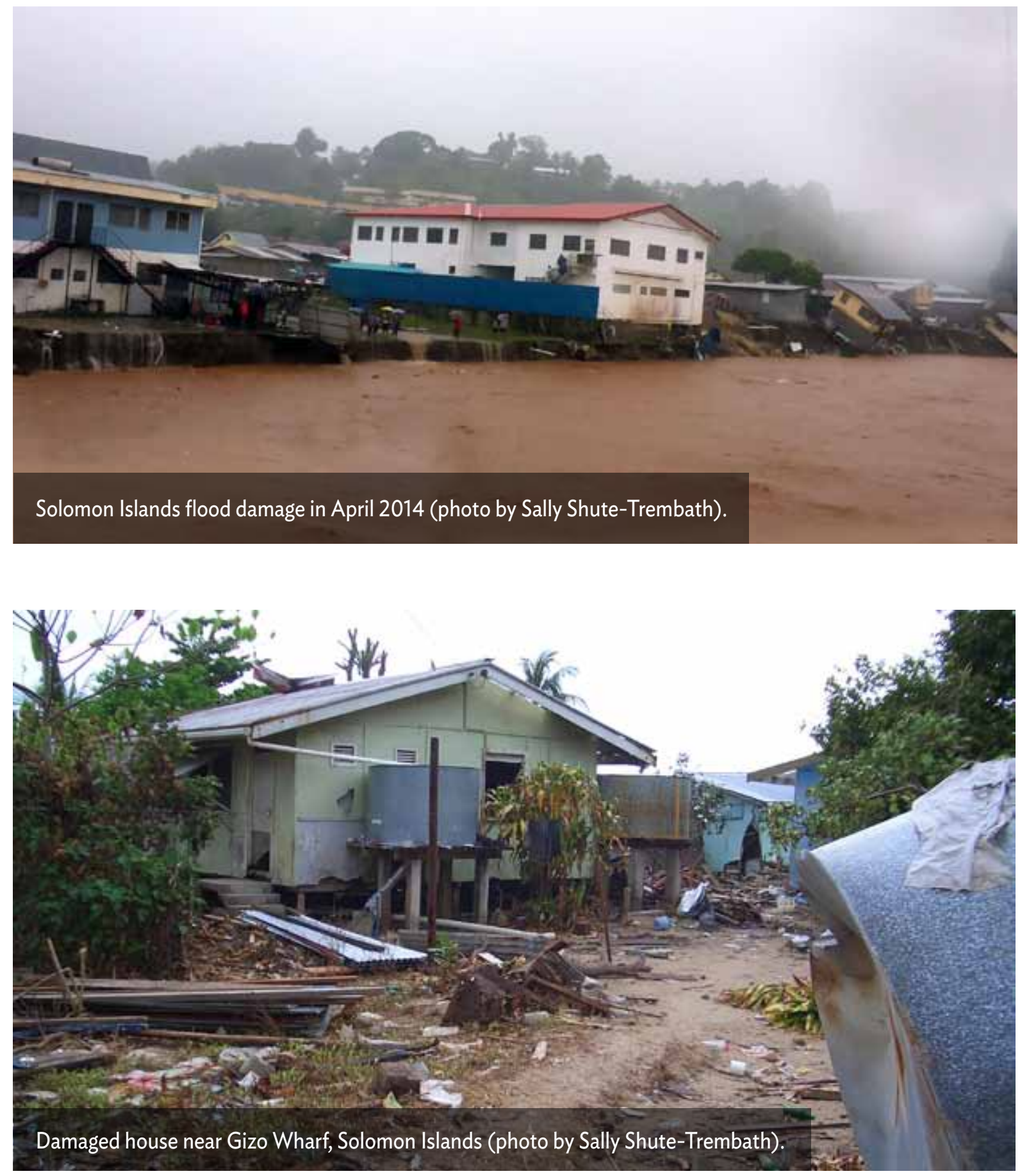


\section{Typology of Disaster Impacts: Direct Damages and Economic Losses}

isaster impacts are typically categorized as direct and indirect. Direct impacts, or damages, include injury, death, and physical damages to infrastructure and assets. Direct damages are incurred during and immediately following a disaster event, and are typically at or near the hazard site. Indirect impacts can be categorized into first order and higher order losses, and are secondary effects, such as halted economic activity, including production of goods and services. Indirect impacts often extend beyond the disaster site, are far-reaching on a time scale, and are, therefore, harder to quantify.

\section{Figure 4: Typology of Disaster Impacts}

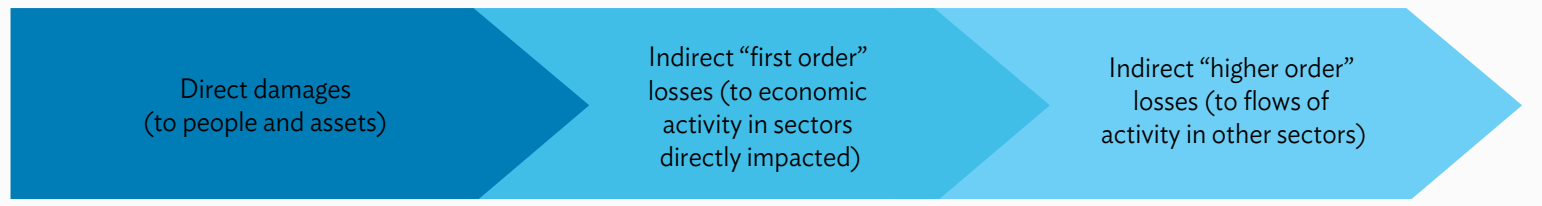

Source: I. Noy. 2016. Tropical Storms: The Socio-Economics of Cyclones. Nature Climate Change. 6. pp. 343-345.

\section{Direct Damages}

Hazard events produce immediate effects on people, communities, and assets. For example, cyclones often destroy homes, productive resources such as farmland, and public infrastructure, as well as cause injury and death. Although there are different methods for counting direct damages, some of the most commonly used metrics include number of deaths, number of people affected, and aggregated economic damages to physical assets.

DRR strategies can significantly attenuate the immediate impacts of disaster. Policy and regulation (such as land-use planning and building codes) influence how development takes place and, in turn, can support more resilient communities and infrastructure. Hard protections (like seawalls and cyclone shelters) can reduce physical risks, but often involve larger capital investments.

To date, high-income countries have typically implemented more robust DRR strategies than low-income countries, which leads to more severe impacts in low-income countries, corresponding to disasters of similar 
magnitudes. ${ }^{14}$ For example, mortality rates are approximately five times higher in low-income countries than they are in high-income countries. ${ }^{15}$ One likely explanation for this is that higher-income countries allocate more resources to DRR and preparedness efforts than those with fewer economic resources, and that they are more prepared to make efficient use of these resources.

Although DRR policies and investments are currently more prevalent in high-income countries, reducing disaster risks does not always require large capital investments. Low-income countries are also capable of adopting successful DRR and preparedness measures. In light of their exposure to hazard events, Pacific DMCs are taking action to strengthen DRR measures, and have made significant progress toward designing policy tools and integrating resilience planning into ongoing infrastructure development.

\section{Box: Strengthening Resilience with Planning and Proactive Investments}

The Pacific is known internationally for its strong community ties. The unique social bonds across the region help mobilize large flows of remittances to respond to disasters, which can help attenuate their economic impacts. It is important that communities, policy makers, and development partners in the region build resilience with forward-thinking policies and investments. The Asian Development Bank (ADB) is supporting proactive resilience planning by providing information and resources to help plan for, manage, and reduce risks; and by climate-proofing its infrastructure investments.

The regional technical assistance Strengthening Climate and Disaster Resilience of Investments in the Pacific is (i) incorporating climate change and disaster risk management considerations into project designs, (ii) integrating climate change and disaster risk management considerations in government planning processes, and (iii) supporting access to climate change financing. As climate change threatens to increase disaster risk profiles across the Pacific, ADB and its development partners are scaling up support to plan for and respond to disaster events.

Source: Author, based on ADB. 2015. Technical Assistance for Strengthening Climate and Disaster Resilience of Investments in the Pacific. Manila.

\section{Economic and Social Losses}

Indirect disaster impacts can cause prolonged hardship for communities in months and years following a disaster. Losses include halted or slowed economic activity in sectors directly affected by damages, as well as broader disruptions to economic flows. First order losses are caused by the immediate impact of a disaster, such as halted agricultural activity due to damaged farmland. Higher order losses are secondary effects on resource flows, such as the reallocation of public funds-from services like education or health care-to meet emergency needs. Indirect losses can halt economic activity, slow development efforts, and, in turn, lead to persistent hardship for people and communities.

Early recovery efforts are essential for minimizing impacts on communities and economies. Understanding the correlation between disasters and economic performance allows policy makers and development partners to effectively plan for and respond to hazard events with appropriate resources. Access to and effective management of early recovery resources, such as external assistance or insurance payouts provided in the

14 This publication defines low-income countries as having a gross domestic product per capita below $\$ 2,000$, and high-income countries as having a gross domestic product per capita above $\$ 14,000$.

15 M. E. Kahn. 2005. The Death Toll from Natural Disasters: The Role of Income, Geography, and Institutions. Review of Economics and Statistics. 87(2). pp. 271-284. 
immediate aftermath, enable countries to quickly restore essential services like health care and education, and operationalize key infrastructure. Restoring public services and productive resources is essential to minimizing economic losses and impacts on fiscal balances.

Although there is an extensive body of research that assesses the direct and indirect impacts of disasters on economic performance, very few studies focus on the Pacific region. Further, although research provides clear insights into the effects of disasters on short-term economic growth, there are considerable limitations in understanding how disasters affect long-term growth and national development.

Short-term impacts on economic growth. Review of international studies indicates that disasters typically have negative effects on short-term economic growth in low-income countries. ${ }^{16}$ Further, short-term impacts are more severe in small or underdeveloped economies than they are in larger ones, and small economies are often less-resilient to shocks. ${ }^{17}$ Although research indicates a clear negative correlation between disaster events and short-term growth, studies fail to provide conclusive explanations of why disasters generate negative impacts on economic outputs.

Further research is needed to distinguish between the impacts of disasters on (i) residential housing, (ii) agricultural production, (iii) public services delivered through infrastructure, and (iv) manufacturing activity. This information is necessary to understand whether economic impacts are transitory or permanent, how they affect the well-being of people and communities, and, in turn, how to proactively respond to immediate disaster impacts more effectively.

Long-term impacts on economic growth. Assessing the long-term impacts of natural disasters on economic growth is challenging because estimates depend, in part, on counterfactual models to project what growth would have been, in the absence of a disaster. Research suggests that, in terms of international averages, natural disasters have little to no impact on long-term economic growth. However, when applying this research to the Pacific, a number of exceptions need to be considered: ${ }^{18}$ (i) the economies of poor countries and small islands appear to be less-resilient to shocks in the long-term; and (ii) the long-term economic impacts of natural disasters are more severe when they trigger radical political change. Disasters in the Pacific have historically produced more political consequences than in other regions. ${ }^{19}$ Given the limited body of available research, it is still difficult to predict what the long-term economic impacts of disasters in the Pacific will be.

16 E. Cavallo and I. Noy. 2011. The Economics of Natural Disasters-A Survey. International Review of Environmental and Resource Economics. 5(1). pp.63-102.

$17 \quad$ G. Felbermayr and J. Groschl. 2014. Naturally Negative: The Growth Effects of Natural Disasters. Journal of Development Economics. 111. pp. $92-106$. Please see list of sources for additional materials.

18 I. Noy and W. du Pont. 2016. The Long-Term Consequences of Natural Disasters-A Summary of the Literature. School of Economics and Finance (SEF) Working Paper in Economics and Finance. No. 02 (2016): Victoria Business School.

19 E. Cavallo et al. 2013. Catastrophic Natural Disasters and Economic Growth. Review of Economics and Statistics. 95(5). Pp. $1549-1561$. 


\section{Fiscal Impacts of Disasters in the Pacific}

O

verall, research on the effects of disaster events on fiscal standing highlights that economic growth and fiscal balances in small and developing economies (like those in the Pacific) are more fragile to disasters than larger, more developed economies. Impacts are clearer in the short term, and differ across types of disasters and country contexts. Although recovery costs can severely affect national economies, unique public revenue structures in many Pacific DMCs appear to minimize the impacts of disasters on public revenue collection. As such, policy makers and development partners in the region should seek to understand the immediate costs of disasters, and identify appropriate financial tools to attenuate lasting impacts.

Post-disaster recovery can impose multiple levels of liability on the public sector, which, in turn, can generate far-reaching impacts on its fiscal sustainability. In addition to the costs associated with emergency response and recovery, the public sector often bears a significant share of broader reconstruction costs. Direct and indirect costs to the public sector can lead to the deterioration of a government's fiscal position-increasing public debt and the cost of borrowing, and decreasing a government's credit rating. In cases where the government

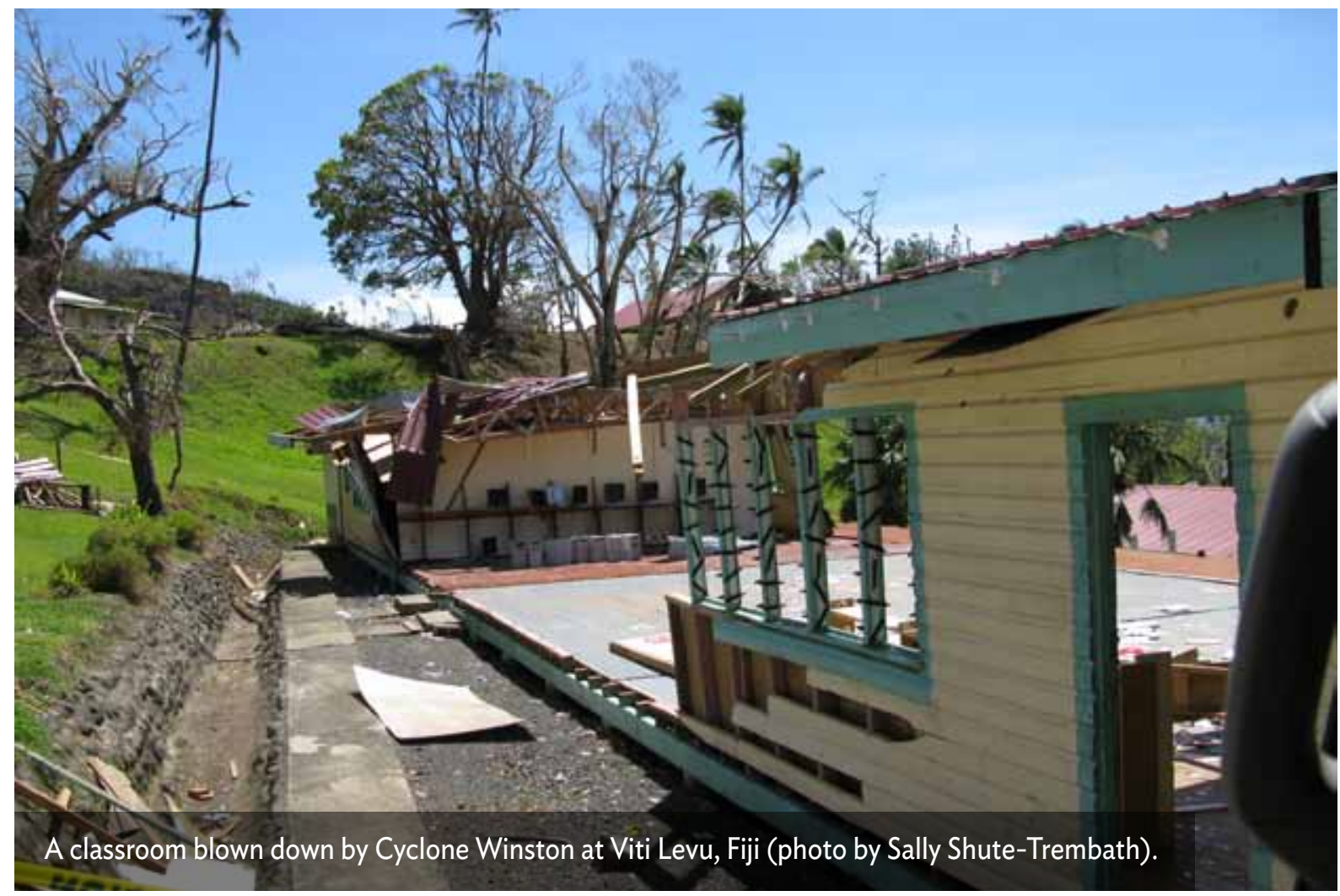


cannot borrow, a deteriorating fiscal outlook may lead to monetization of deficits and consequent inflationary pressures, or reductions in spending in other needed areas.

Accurate projections of the fiscal costs of disasters are, therefore, important for fiscal planning. Understanding immediate reconstruction and recovery costs, and how they impact fiscal standing, is essential for selecting appropriate financial instruments to recover from disasters and attenuate impacts on national economies and fiscal standing.

\section{Post-Disaster Expenditures}

Primary costs to the public sector, following a disaster, often include (i) emergency services and relief; (ii) reconstruction of public infrastructure and buildings; (iii) reconstruction of underinsured or uninsured housing; (iv) expenditures on social, employment, and economic recovery programs (such as investments in new businesses or social services); and ( $v$ ) payments for the liabilities and investment needs of state-owned enterprises.

The logistical complexities of recovery efforts in the Pacific, such as delivering resources to highly dispersed communities, can amplify the costs of responding to disasters. As such, public reconstruction costs in the Pacific tend to be significantly higher than the value of the destroyed capital assets.

\section{Post-Disaster Revenue Collection in the Public Sector}

In addition to direct costs, the public sector can encounter indirect fiscal burdens, such as (i) decreased tax revenues corresponding to lower incomes and reduced taxable economic activity; (ii) the need to provide tax deductions or tax rate cuts to assist recovery; and (iii) diversion of public funds from sustainable growth programs, to address emergency needs.

Although decreased revenue is an important consideration for understanding fiscal impacts of disaster events, internationally, this particular impact may be less-damaging to Pacific economies than those in other regions. This is the case because revenue sources for governments in the Pacific are less-sensitive to fluctuations in domestic economic activity than what is typical in larger, more developed economies.

Income and corporate taxes represent only modest contributions to government revenue in many Pacific DMCs, and primary revenue sources-including exports of natural resources, import taxes, and development assistance-do not typically decrease following disaster events. Natural resource exports, for example, are unlikely to be affected by hazard events because demand does not fluctuate much as a consequence of disasters. Although imports of consumer goods may decrease in the aftermath of disasters-particularly if transport infrastructure, such as ports, are destroyed-imports of materials for reconstruction often balance tariff fluctuations. From a fiscal perspective, it is also important to note that official development assistance typically increases following disaster events, which helps attenuate fluctuations

Further, since most Pacific DMCs rely on the currencies of larger global economies or maintain fixed pegs through constraints on capital flows, post-disaster exchange rate movements are unlikely. As a result, the overall revenue of Pacific DMCs does not typically decrease much as a result of disasters. 


\section{Building Financial Resilience in the Pacific}

esponding to disasters rapidly enables countries to minimize impacts on people and socioeconomic development. However, most Pacific DMCs have limited financial capacity to prepare for and recover from disasters. Corresponding delays in disaster recovery exacerbate indirect social and economic costs, increase long-term impacts, and can lead to the deterioration of a country's fiscal standing. As climate change and rising sea levels continue to increase risk profiles across the Pacific, it is essential that countries in the region adopt new strategies to manage risks and build fiscal resilience.

The most cost-effective method to finance disaster recovery is to leverage a range of tools, designed to address different levels of risks. Some of the key tools for financing disaster recovery are already available to Pacific DMCs; these include insurance policies, contingent credit lines, and national disaster funds. However, products are still limited in scope and in number, and most Pacific DMCs do not avail of the full range of existing tools. Furthermore, policy conditions do not currently support the efficient use of the range of financial products.

The Tool Kit for Financial Resilience in the Pacific outlines the key financial products that are available (or can be made available) to Pacific DMCs, as well as corresponding opportunities, challenges, and potential solutions associated with each. ADB is committed to supporting increased social, economic, and fiscal resilience across the Pacific, and will continue to finance projects and technical assistance to support DRR and financial preparedness for its Pacific DMCs.

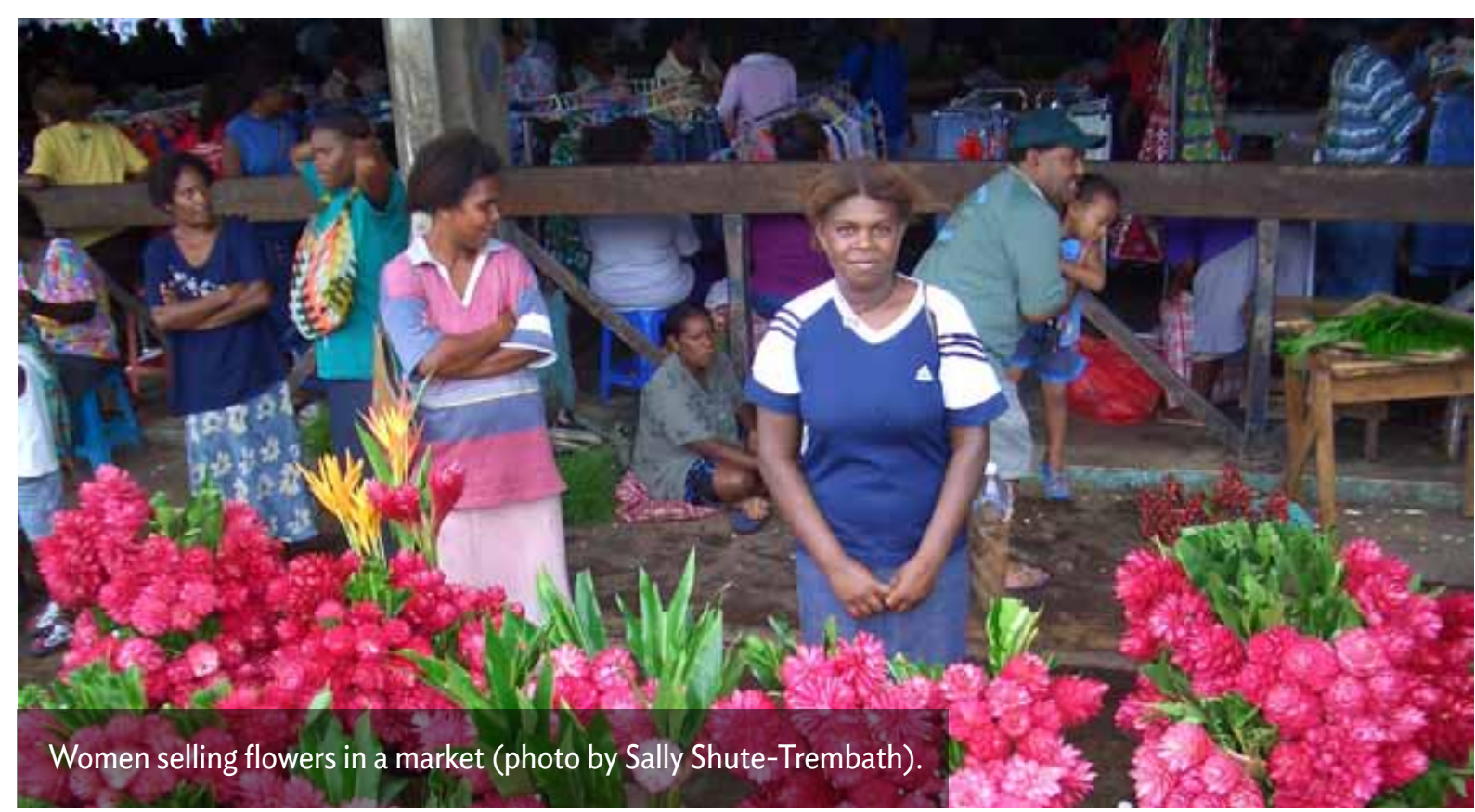




\section{Tool Kit for Financial Resilience in the Pacific}

\begin{tabular}{|c|c|c|}
\hline Tool & Description and Challenges & Solutions and Opportunities \\
\hline $\begin{array}{l}\text { Post-disaster } \\
\text { budget } \\
\text { provisions } \\
\text { (national } \\
\text { disaster funds) }\end{array}$ & $\begin{array}{l}\text { Description: } \\
\text { National disaster funds are annual budget } \\
\text { allocations that governments use to respond to } \\
\text { disaster events. They are typically used to meet } \\
\text { recurrent costs associated with frequent, low- } \\
\text { impact events, such as floods and droughts. } \\
\text { Challenges: }\end{array}$ & $\begin{array}{l}\text { Solutions: } \\
\text { One option for addressing resource constraints } \\
\text { is for policy makers to establish provisions for } \\
\text { redirecting existing budgets to meet the needs of } \\
\text { emergency costs, prior to disaster events. To assist } \\
\text { governments in transferring risk, it is important to } \\
\text { complement disaster funds with parallel financial } \\
\text { tools. }\end{array}$ \\
\hline
\end{tabular}

Funds are typically too small to meet recovery needs, and most of the Pacific developing member countries (DMCs) of the Asian Development Bank (ADB) cannot afford to increase the size of their disaster funds. Since disaster funds are often used to respond to frequent low-impact hazard events, funds are often depleted annually, and are insufficient to respond to less-frequency, highimpact disasters. Although disaster funds are an essential tool to meet recovery needs, they do not transfer risk.

\section{Opportunities:}

Defining sources from which to reallocate funds can help streamline emergency budget allocations when they are necessary. This approach can help governments respond to emergency needs more effectively, and recover from disasters more swiftly. Aligning disaster funds with other financial tools helps ensure that governments have funds that can be quickly released, while also transferring financial risks.

\section{Offshore provident funds}

\section{Description:}

Many Pacific DMCs maintain sovereign wealth and provident funds invested offshore. These can be used to meet emergency response needs, and can be particularly effective for financing disaster responses for infrequent, high-impact disaster events.

\section{Challenges:}

As is the case with disaster funds, offshore provident funds do not help transfer financial risk. Furthermore, accessing funds can be more timeconsuming than mobilizing disaster funds.

\section{Solutions:}

Policy makers can work with fund managers to establish trigger mechanisms associated with disaster events. Doing so allows governments to access funds in the immediate aftermath of large disaster events.

\section{Opportunities:}

Offshore sovereign wealth and provident funds can play an essential role in meeting emergency recovery needs, and can be quickly mobilized, provided that prearranged trigger events are established to streamline the process. 
Table continued

Tool

Contingent

Credit line

facilities (from

development

partners)
Description and Challenges

Description:

ADB and the World Bank have established facilities to release prearranged loans when specific trigger events occur. The purpose of prearranged credit lines is to finance early recovery needs, such as temporary reconstruction of essential communication or transport facilities, like cell towers of ports.

\section{Challenges:}

Contingent credit lines are not intended to meet emergency recovery needs, and are not released immediately. They are intended to complement other financing mechanisms, and are, therefore, not sufficient to meet all early recovery needs.
Contingent grants and loans from development partners

\section{Description:}

Grants, loans, and financing facilities that are earmarked to address climate change may provide additional sources of financing to meet disaster risk reduction needs (such as investments in resilient infrastructure) as well as post-disaster recovery. The Green Climate Fund (GCF) is a major international financing facility designed to meet climate change mitigation and adaptation needs. The Warsaw International Mechanism for Loss and Damage (WIM) is being designed to meet financing needs for damages and losses associated with climate change.

\section{Challenges:}

GCF financing is currently lower than anticipated, and will require further contributions to be brought to scale. Although WIM may provide a viable source of support in the future, it is still being developed. Furthermore, accessing GCF resources is a complex process, and requires that recipients be accredited agencies. Due to the complicated accreditation process, smaller Pacific DMCs will continue to rely on accredited organizations - such as ADB and the United Nations Development Programme-to access financing. Larger Pacific DMCs may be capable of receiving accreditation in the future, but currently depend on accredited agencies to access $\mathrm{GCF}$ resources.

\section{Solutions and Opportunities}

\section{Solutions:}

Development partners may consider methods for disbursing contingent credit lines more swiftly, and can also consider increasing the size of available funds. Furthermore, development partners may choose to convert specific credit lines into grants, to transfer risk away from Pacific DMCs to the international community.

\section{Opportunities:}

Contingent credit lines help smooth government spending, and typically provide subsidized interest rate margins. Identifying ways to release contingent credit lines more rapidly can help countries finance disaster response and recover from disasters more quickly. Doing so can reduce long-term impacts on people, the economy, and fiscal standing.

\section{Solution:}

$A D B$ is accredited to receive GCF financing, and can assist Pacific DMCs to access corresponding grant resources to meet both mitigation and adaptation needs. ADB and other accredited agencies can further assist Pacific DMCs by building domestic capacity to apply for climate and disaster financing from GCF and WIM (once it is established).

\section{Opportunities:}

Grants and loans from development partners currently play a major role in assisting Pacific DMCs to increase resilience and respond to disaster events. Although GCF and WIM are both relatively young mechanisms, they will play a key role in scaling up grant financing to overcome challenges associated with climate change. Loans from development partners will continue to be essential for building climate-resilient infrastructure, and for rebuilding assets after disaster events.

Note:

The Cook Islands became the first Pacific DMC to access GCF financing, and received $\$ 150,000$ in 2016 to build domestic capacity to support it in accessing further GCF financing. This sets a precedent for other Pacific DMCs to collaborate with development partners to access climate finance through the GCF mechanism. 
Table continued

\begin{tabular}{|c|c|c|}
\hline Tool & Description and Challenges & Solutions and Opportunities \\
\hline $\begin{array}{l}\text { Insurance for } \\
\text { public assets }\end{array}$ & $\begin{array}{l}\text { Description: } \\
\text { Governments and public sector entities can insure } \\
\text { assets, such as ports, airports, and other key } \\
\text { lifelines, which are vulnerable to hazard events } \\
\text { and are costly to repair. Since functional public } \\
\text { infrastructure is both costly and essential for } \\
\text { restoring economic activity, asset owners in Pacific } \\
\text { DMCs should consider options for securing key } \\
\text { assets. } \\
\text { Challenge: } \\
\text { Currently, very few countries in the Pacific and } \\
\text { elsewhere insure public assets. This is the result } \\
\text { of the lack of appropriate insurance products }\end{array}$ & $\begin{array}{l}\text { Solution: } \\
\text { Development partners may be able to support } \\
\text { governments in the Pacific to access insurance for } \\
\text { public assets by helping meet or reduce the cost } \\
\text { of underwriting. One option is for development } \\
\text { partners to directly finance premiums on behalf } \\
\text { of the DMC. Another option, which may provide } \\
\text { a more sustainable solution, is for development } \\
\text { partners to help lower the cost of insurance by } \\
\text { negotiating bulk purchases of insurance contracts } \\
\text { in the region. A third option is for development } \\
\text { partners to directly provide insurance products at } \\
\text { accessible rates. }\end{array}$ \\
\hline
\end{tabular}
for doing so, and the corresponding high cost of existing products. Having little or no coverage for public assets exposes countries to high costs of reconstruction, which can overwhelm government budgets in the aftermath of disasters.

\section{Opportunity:}

Increasing insurance coverage can help transfer risk, and insulate against major expenditure associated with repairing essential and costly public infrastructure in the aftermath of disasters.

\section{Private Description:}

insurance

\section{Description:} develop products to cover publicly owned assets, or issue sovereign insurance coverage. PCRAFI is one such model, under which a private entity issues private insurance for five participating countries.

\section{Challenges:}

Public and private assets in the Pacific region are typically underinsured because there are a limited number of insurance products in the region. At the same time, low demand for insurance products has not encouraged providers to develop extensive products, and the lack of available information needed for private firms to assess risk data makes it difficult for them to develop appropriate products. Furthermore, the limited access of many Pacific communities to financial institutions makes it difficult for them to purchase private insurance.

\section{Solutions:}

The public sector can encourage private insurance providers to offer a wider range of products by providing risk data, and by supporting private firms in accessing it. Pacific Catastrophe Risk Assessment and Finance Initiative (PCRAFI) is one such initiative, which may support financial institutions to develop new insurance products. PCRAFI enables insurance providers to assess and price risk more accurately, by providing local risk data.

Both ADB and the World Bank are involved in initiatives to increase community access to financial institutions, as well as to increase the size of the insurance sector in low- and middle-income countries. Mobile banking initiatives are increasing access to financial institutions and, in turn, may allow local financial institutions to provide micro insurance contracts and innovative products, such as crop index insurance.

\section{Opportunities:}

A wider range of available insurance products can alleviate fiscal burdens associated with post-disaster response and, in turn, attenuate sociopolitical pressures to allocate public resources for reconstruction. The public sector can encourage private financial institutions to increase the number and quality of insurance products. 
Table continued

\begin{tabular}{ll} 
Tool & \multicolumn{1}{c}{ Description and Challenges } \\
Sovereign & Definition: \\
insurance & Sovereign insurance products provide lump \\
and pooled & sum payments to governments when trigger \\
sovereign & events occur. Sovereign insurance is issued by \\
insurance & multinational reinsurance companies, and typically \\
& requires subsidies from development partners.
\end{tabular}

Regional insurance pool arrangements are a way to collate resources and share risk across countries and, in turn, to reduce the cost of underwriting. Pooled sovereign insurance can lower the cost of underwriting by distributing the costs of modeling risk and legal expertise, and by providing access to international reinsurance. The PCRAFI is one example of this model.

\section{PCRAFI:}

In 2013, PCRAFI launched a subsidized insurance product that provides semi-parametric coverage to participating countries. It insures against earthquakes and tropical cyclones in the Cook Islands, the Marshall Islands, Samoa, Tonga, and Vanuatu.

National coverage is a function of the risk profile constructed for each country (based on the data on hazard frequencies and exposure of physical assets) and the country's choice of coverage. Coverage for physical assets includes cash crops, public infrastructure, and buildings.

\section{Challenges:}

The central barriers to sovereign insurance in the Pacific are the limited number of products, and their limited scope of coverage. Although PCRAFI illustrates progress toward scaling insurance coverage in the region, it is limited in a number of ways. Currently, PCRAFI is the only sovereign insurance program in the Pacific, and does not provide sufficient coverage to insulate against the full range of hazards and damages. Vanuatu, for example, was insured for less than $\$ 2$ million for Cyclone Pam.

\section{Solutions and Opportunities}

\section{Solutions:}

Development partners can work with multilateral reinsurance providers to discuss methods for providing additional facilities. Other potential solutions include modifying PCRAFI in order to increase the scope of coverage; redefine or eliminate the parametric nature of coverage; or consider options for providing direct reinsurance for DMCs, as opposed to doing so through the private sector. Although these methods may provide significant benefits to Pacific DMCs, they also require complex and high-level discussions, and may be difficult to actualize in the short term.

\section{Opportunities:}

Increasing the availability and use of pooled sovereign insurance coverage can help insulate Pacific DMCs against damages and losses. PCRAFI is an essential first step toward increasing the financial resilience of Pacific DMCs to the effects of disaster events, and may encourage further development of sovereign insurance products in the region. 
Table continued

Tool Description and Challenges Solutions and Opportunities

Catastrophe bonds (CAT bonds)

\section{Description:}

CAT bonds are a type of bond whereby the borrower's debt is erased (either in part or in full) in the case of specific trigger events. Although they do not provide funding for recovery or reconstruction, CAT bonds can be used to finance risk reduction and resilient infrastructure, such as seawalls or other hard protections.

\section{Challenges:}

The majority of existing catastrophe bonds (CAT bonds) have been issued for high-income countries, or for specialized insurance companies, because CAT bonds require specialized institutional capacity and financial market depth.

\section{Solutions:}

Countries can issue CAT bonds directly with the private sector, or through development partners. In the Pacific context, development partners are the most likely vectors for issuing CAT bonds. One option for doing so is for development partners to issue CAT bonds on a contingent basis. For example, development partners may consider providing CAT bonds only if a borrower meets specific conditions, such as developing climate change action plans.

\section{Opportunities:}

CAT bonds can enable countries to access financing for resilient infrastructure and increase disaster preparedness. Contingent issuance of CAT bonds can build investor confidence by indicating that a given nation is taking measures to reduce disaster risk. Investor confidence, in turn, can translate to reduced cost of borrowing. As such, CAT bonds may provide an effective vehicle for enabling Pacific DMCs to finance disaster risk management and, at the same time, encourage resilience planning and policy actions.

continued on next page

Figure 5: Applying the Tool Kit to Varying Disaster Types
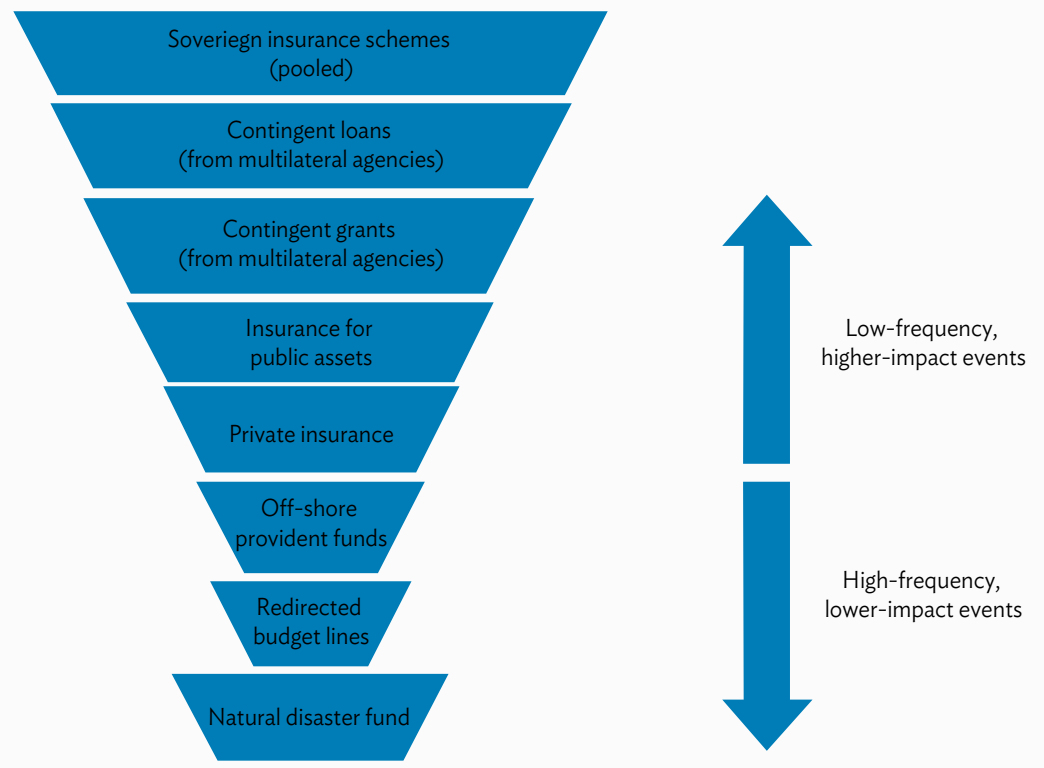
Table continued
Tool
Description and Challenges
Solutions and Opportunities

\section{ADDITIONAL DISASTER RISK REDUCTION STRATEGIES}

\section{Early warning} systems

\section{Definition:}

Early warning systems are technology solutions that alert stakeholders to inbound hazard events or threats, and allow them to take preparatory actions. In the Pacific region, most common are early warning systems alert authorities to tsunamis and cyclones.

\section{Challenges:}

Early warning systems require up-front investments, as well as continued resources to ensure proper operation and maintenance. Furthermore, although systems can help alert and prepare for threats, managing systems effectively also requires that appropriate policies and education programs are in place to ensure that all stakeholders know how to respond to a hazard.

For example, in order for an early warning system to provide value at the time of a disaster, authorities need to be trained on how to safely evacuate populations.
Land-use planning and other policy tools

\section{Definition:}

Land-use planning, zoning laws, and building codes are policy tools that can help reduce the exposure of populations and assets to hazard events. Policy makers in the Pacific should focus efforts on areas that are highly exposed, such as river valleys, steep hillsides, and coastal areas.

\section{Challenges:}

These policy tools require capacity to analyze and plan for hazard events, as well as political buy-in to encourage policy development and corresponding regulation. Human resources and corresponding technical capacity are often in short supply in the Pacific.

Integrated resource planning

\section{Definition:}

Disaster risk reduction and risk mitigation plans should be integrated into infrastructure development. As Pacific DMCs continue investing in transport, energy, and other key infrastructure resources, it is essential to ensuring that assets are designed to be resilient to hazards, whenever possible.

\section{Challenges:}

Integrating resilience planning into project design can increase upfront project costs, and make capital investments more expensive. This is sometimes met with political resistance, particularly in cases where leadership does not recognize the value of resilience planning.

\section{Solution:}

Policy makers can integrate early warning systems into national development planning. These tools are particularly relevant in the Pacific region, due to the high incidence of natural hazards.

\section{Opportunities:}

Early warning systems can reduce death, morbidity, and damages associated with hazard events.

\section{Solutions:}

Development partners can assist national governments and corresponding ministries to integrate land-use planning and other policy tools into national development.

\section{Opportunities:}

Land-use planning is an inexpensive method for reducing the exposure of communities and assets to the impacts of disasters. Designing policies and regulations to support land-use planning can significantly reduce direct and indirect damages.

\section{Solution:}

The principles of resilient development should be built into project design and national policies. The Secretariat of the Pacific Community is assisting governments across the Pacific to design joint national action plans to respond to climate change and manage associated risks. These plans provide an effective venue for collating disaster risk reduction strategies, and integrating them into national planning.

\section{Opportunities:}

Resilient infrastructure can significantly reduce costs and damages associated with disasters. As such, even in cases where resilient infrastructure design may increase up-front development costs, building assets to withstand hazard events reduces risks associated from the medium to long term. 


\section{Economic and Fiscal Impacts of Disasters in the Pacific}

Climate change and natural disasters can have lasting consequences on livelihoods, economies, and fiscal balances-spanning immediate reconstruction costs and fiscal shocks to long-term halts in tourism and agriculture economies. Globally, the most exposed to these impacts are the Pacific island countries. The Asian Development Bank is working closely with its Pacific developing member countries to prepare for and respond to the effects of climate change and natural hazards. This publication examines the often-overlooked dimension of resilience planning-how to brace economies for shocks caused by climate change and hazard events. It analyzes the exposure and vulnerability of Pacific economies to disaster events and outlines key resources for building fiscal and economic resilience.

\section{About the Asian Development Bank}

ADB's vision is an Asia and Pacific region free of poverty. Its mission is to help its developing member countries reduce poverty and improve the quality of life of their people. Despite the region's many successes, it remains home to a large share of the world's poor. ADB is committed to reducing poverty through inclusive economic growth, environmentally sustainable growth, and regional integration.

Based in Manila, ADB is owned by 67 members, including 48 from the region. Its main instruments for helping its developing member countries are policy dialogue, loans, equity investments, guarantees, grants, and technical assistance. 